\title{
Mean Platelet Volume in Early Diagnosis of Adnexal Torsion
}

\author{
Iş11 Köleli \\ Department of Gynecology and Obstetrics, İnönü University Faculty of Medicine, Malatya, Turkey
}

Background: Adnexal torsion (AT) is among the gynecological emergencies; more common in reproductive age, if diagnosed late, this can cause ovarian failure and infertility, but rarely thrombophlebitis and peritonitis. Despite these severe complications, preoperative diagnostic tests are not enough for early diagnosis. There are certain pieces of literature on the subject that reveal changes in mean platelet volume (MPV) values occur in inflammatory and ischemic diseases and that these changes have diagnostic and prognostic significance. However, there are no studies investigating this relationship with adnexal torsion.

Aims: The aim of the study is to investigate the diagnostic and prognostic significance of the mean platelet volume value in the early diagnosis of patients with adnexal torsion.

Study Design: Case-control study.

Methods: Pre-operative demographic data, MPV, leukocyte count and neutrophils to lymphocytes (N/L) ratio in the blood samples of 51 patients, who were operated on preliminary adnexal torsion and diagnosed as adnexal torsion with a benign ovarian cyst (AT group) were retrospectively compared with those of 50 patients who were operated upon because of benign ovar- ian cysts and without torsion (control group) at this hospital between 2006 and 2014.

Results: The mean MPV level was found to be 8.1 (7.1-10.7) $\mathrm{fL}$ in the AT group and 7.9 (6.6-10.2) $\mathrm{fL}$ in the control group; no statistically significant difference was found between the groups ( $\mathrm{p}>0.05$ ).

Leukocyte count and N/L ratio in the AT group were, on average, $12 \times 10^{3} / \mathrm{mm}^{3}$ and $82 \%$ respectively and in control group; they were, on average, $7.2 \times 10^{3} / \mathrm{mm}^{3}$ and $59 \%$, respectively. A statistically significant increase was found in the leukocyte count and N/L ratio of the AT group compared to the control group $(\mathrm{p}<0.001)$. The platelet count in the AT group was, on average, $253 \times 10^{3 /}$ $\mathrm{mm}^{3}$ and in the control group it was, on average, $280 \times 10^{3} /$ $\mathrm{mm}^{3}$; no statistically significant difference was detected between these two groups ( $p>0.05)$. No correlation was detected between the MPV, platelet and leukocyte counts. The sensitivity of the leukocytosis to the AT cases was found to be $66.7 \%$, and selectivity was $94 \%$.

Conclusion: The AT diagnostic and prognostic importance of MPV value has not been determined in this study. Keywords: Adnexal torsion, mean platelet volume, neutrophils to lymphocytes ratio, platelet, leukocyte, leukocytosis
Adnexal torsion (AT) is a gynecological emergent pathology which develops as a result of obstruction of adnexal arterial and venous flow, generally by rotation of the ovary together with the tuba or rarely because of the tuba's rotation around itself(1). With the deterioration of arterial flow, edema and ischemia may develop in the tissue, and if detorsion is not performed, necrosis may develop. In cases where the pathology persists, fatal pelvic thrombophlebitis and peritonitis may develop (2).

In general, $70-80 \%$ of adnexal torsion cases are seen in reproductive age individuals (3). Delays in treatment may re- 
sult in the loss of ovarian function and infertility. Although early diagnosis and treatment have a protective effect on fertility, there is not yet a specific diagnostic test that may help the clinician in diagnosing adnexal torsion. Torsion has been monitored in only $46 \%$ of patients who were operated on with adnexal torsion pre-diagnosis (4).

Mean platelet volume (MPV) is a parameter that is assessed in routine blood samples. Numerous studies have shown that the construction and activation of platelets increase in inflammatory and ischemic pathologies and accordingly changes occur in the MPV values $(5,6)$. The diagnostic importance of MPV has been shown in diseases such as acute appendicitis, pelvic inflammatory and ectopic pregnancy (7-9). To date, there has been no study investigating the relationship between the MPV and adnexal torsion.

The aim of this retrospective study is to investigate the diagnostic and prognostic importance of the MPV value in the early diagnosis of AT.

\section{MATERIALS AND METHODS}

Clinical files of 51 patients who were operated upon with AT pre-diagnosis and diagnosed with AT and have a benign ovarian cyst (AT group) and 50 patients who were operated upon and reported as having a benign ovarian cyst (control group) were examined retrospectively at the Department of Gynecology and Obstetrics of Turgut Özal Medical Center (TOTM) of İnönü University between 2006-2014. Ethical approval was obtained from the Institutional ethical committee of Inonu University. Written informed consent for further clinical research was given by participants. As a result of adnexal masses pathology, mature cystic teratoma, follicular cyst, corpus luteum cyst, serous cystadenoma, mucinous cystadenoma were taken as benign ovarian cysts. Physical examination, laboratory tests and color Doppler sonography were performed in those patients who applied to our clinic with immediate pelvic pain, nausea and vomiting complaints. Laparotomy was performed for patients with AT pre-diagnosis. Adnexal torsion diagnosis was made upon seeing, during the operation, that the adnexa rotated at least 360 degrees around itself.

The platelet count, leukocyte count, neutrophil to lymphocyte $(\mathrm{N} / \mathrm{L})$ ratio and MPV in blood samples of the patients were compared. Those patients who had malignancy, endometriosis, malignant adnexal mass, a chronic systemic disease and acute inflammatory disease, and those on drugs and pregnant patients were not included in the study as their situation might affect MPV values, platelet count, leukocyte count and N/L ratio.

In TOTM, all of the blood samples are put into tubes containing EDTA (Potassium ethylenediamine tetra acetic acid) as the anticoagulant agent. Blood samples are analyzed within an hour at the hematology laboratory.

\section{Statistical analysis}

All analyses were performed using Statistical Package for the Social Sciences (SPSS) (SPSS 16.0, Chicago, USA). Using theoretical power analysis, it was calculated that there should be at least 46 patients in each group when the difference between the experiment control group was 0.96, standard deviation was 1.4 , type I error $(\alpha)=0.05$ and type II error $(\beta)=0.1$. As the data did not give a normal distribution, median, minimum and maximum values were given as descriptive. The Mann-Whitney U test and Kruskal Wallis test were used for comparisons. Significance level was accepted as $\mathrm{p}<0.05$.

\section{RESULTS}

The number of patients who were operated upon with adnexal torsion pre-diagnosis and had AT (AT group) was 51, and the number of the patients who were operated upon for adnexal masses and not identified with torsion (control group) was 50 .

Mean platelet volume, platelet count, leukocyte count and $\mathrm{N} / \mathrm{L}$ ratio in blood samples and their ages were compared between the two groups (Table 1).

The average age in the AT group was $32( \pm 9)$ and in the control group was 33; no statistically significant difference was found between the two groups.

The N/L ratio was higher in the AT group compared with the control group (82\% (range, 50-93\%); 59\% (range, 45-89\%)). The increase in the neutrophil ratio in the patients with AT when compared with the control group was statistically significant $(\mathrm{p}<0.001)$.

The MPV value in the AT group was 8.1 (range, 7.1-10.7) $\mathrm{fL}$, whereas in the control group it was 7.9 (range, 6.6-10.2) fL. There was no statistically significant difference according to MPV values $(\mathrm{p}=0.07)$.

The mean platelets count in the AT group was 253 (range, $156-493) \times 10^{3} / \mathrm{mm}^{3}$, whereas in the control group, it was 280 (range, $135-401) \times 10^{3} / \mathrm{mm}^{3}(\mathrm{p}=0.78)$. There was no statistically significant difference according to MPV values.

Leukocyte counts in the AT group were higher than those of the control group (12000 (range, 4800-32900)/ $\mathrm{mm}^{3}$ and 7250

TABLE 1. Comparison of the demographic features and leukocyte count, $\mathrm{N} / \mathrm{L}$ ratio, MPV levels, and platelet counts in AT and control groups

\begin{tabular}{lccc} 
& $\begin{array}{c}\text { AT Group } \\
(\mathrm{n}=51)\end{array}$ & $\begin{array}{c}\text { Control Group } \\
(\mathrm{n}=50)\end{array}$ & $\begin{array}{c}\mathrm{p} \\
\text { value }\end{array}$ \\
\hline Age & 32 & 33 & 0.82 \\
Leukocyte $\left(\mathrm{mm}^{3}\right)$ & $12000(4800-32900)$ & $7250(4600-13100)$ & $<0.001$ \\
N/L ratio $(\%)$ & $82(50-93)$ & $59(45-89)$ & $<0.001$ \\
MPV (fL) & $8.1(7.1-10.7)$ & $7.9(6.6-10.2)$ & 0.07 \\
Platelet $\left(10^{3} \mathrm{xmm}^{3}\right)$ & $253(156-493)$ & $280(135-401)$ & 0.78 \\
\hline
\end{tabular}

AT: adnexal torsion; N/L: neutrophils to lymphocytes; MPV: mean platelet volume 
TABLE 2. Pathological findings of ovarian cysts

\begin{tabular}{lcc}
\hline & AT group $(\mathrm{n}=51)$ & Control Group $(\mathrm{n}=50)$ \\
\hline Mature cystic teratoma & $20(39.2 \%)$ & $11(22 \%)$ \\
Follicular cyst & $14(27.4 \%)$ & $4(8 \%)$ \\
Corpus luteum cyst & $9(17.6 \%)$ & $13(26 \%)$ \\
Serous cystadenoma & $4(7.8 \%)$ & $19(38 \%)$ \\
Mucinous cystadenoma & $4(7.8 \%)$ & $3(6 \%)$ \\
\hline
\end{tabular}

AT: adnexal torsion

TABLE 3. Leukocytosis ratio in AT and control groups

\begin{tabular}{lccc}
\hline Leukocytosis & Positive & Negative & Total \\
\hline AT group (\%) & 66.7 & 33.3 & 100 \\
Control group (\%) & 6 & 94 & 100 \\
\hline AT: adnexal torsion & & &
\end{tabular}

TABLE 4. Correlation Analysis of MPV, Platelet, Leukocyte, N/L ratio

\begin{tabular}{lcc}
\hline Parameters & Correlation Coefficient $(\mathrm{r})$ & $\mathrm{p}$ value \\
\hline MPV-Platelet & 0.091 & 0.36 \\
MPV-Leukocyte & 0.191 & 0.05 \\
MPV-N/L ratio & 0.159 & 0.11 \\
Leukocyte-N/L ratio & 0.745 & $<0.001$ \\
\hline
\end{tabular}

MPV: mean platelet volume; N/L: neutrophils to lymphocytes

(range, 4600-13100)/ $/ \mathrm{mm}^{3}$ ). A statistically significant increase in the leukocyte count was detected in the AT group compared with the control group $(\mathrm{p}<0.001)$.

When pathology results were compared, in the AT group, the mature cystic teratoma ratio was found to be $39.2 \%$. In the control group; mostly, serous cystadenoma was identified (38\%) (Table 2).

Leukocytosis ratio was $66.7 \%$ in the AT group and $6 \%$ in the control group. Leukocytosis ratio was significantly higher than that in the control group. The sensitivity of leukocytosis was found to be $66.7 \%$, and its selectivity was $94 \%$ (Table 3).

According to Spearman's correlation test, there was no correlation between MPV value, leukocyte counts and platelet counts. There was a correlation between leukocyte counts and $\mathrm{N} / \mathrm{L}$ ratio $(\mathrm{r}=0.745 ; \mathrm{p}<0.001$; Table 4$)$.

\section{DISCUSSION}

Adnexal torsion is one of gynecologic emergencies, which are more common in reproductive age, requiring early diagnosis and treatment for the preservation of the fertility. Its frequency in the gynecological emergency operations ranges from 2.5 to $7.4 \%$ (10). In adnexal torsion etiology, ovarian cysts and mostly mature cystic teratoma were detected (2). In a study by Erdemoğlu et al. on 143 cases of adnexal torsion, they found that forty of them were diagnosed as a benign cystic teratoma (11). In one of their studies, Balci et al. detected that mature cystic teratoma was the most frequent pathology in adnexal torsion cases (32\%) (12). Likewise, in accordance with the literature, in this study, mature cystic teratoma has been found to be the most frequent pathological finding.

In the patients, symptoms such as abdominopelvic pain, nausea and vomiting, and findings such as fever and peritoneal irritation may be detected; however, these symptoms and findings may also be found in other pathologies such as acute appendicitis, inflammatory bowel disease, ovarian cyst rupture, and pelvic inflammatory disease; therefore, there are no torsion-specific symptoms and findings $(2,13)$.

Sommerville et al. (14), in one of their studies, found that there was a 12.9-fold-increase in torsion risk in benign adnexal masses, compared with malignant masses and have argued that the invasion of malignant masses to surrounding tissues might prevent torsion.

In many of the studies, leukocytosis was detected as in the rate of $36.5-64 \%$ in preoperative blood samples of the patients who were diagnosed with adnexal torsion (15-17). In this study, the leukocytosis rate in the torsion group compared to the control group was detected to be higher in statistical significance $(66.7 \%$ and $6 \%)$. It has been observed that inflammatory mediators (prostaglandins and cytokines), released with ischemia and congestion occurring as a result of adnexal torsion, cause an increase in the number leukocytes.

A review of MEDLINE in English for the period from 19662014 did not yield any article on the relationship between adnexal torsion and MPV. This is the first study investigating the relationship between MPV and the AT.

In the case of inflammation and thrombosis, platelet production and activation increased. An increase in MPV values is an indicator of an increase in platelet production, and an increase in the number of young and large platelets (18). It has been shown that some cytokines increase the production of more reactive large platelets such as interleukin-3 and interleukin-6 (5). MPV can be assessed routinely in hematological analyses. It has been shown that MPV was at low levels in diseases with high degrees of inflammation such as rheumatoid arthritis and familial Mediterranean fever (19). In some of the retrospective case-control studies performed in acute appendicitis cases, MPV value was low and statistically significant in the acute appendicitis group, and in some studies, MPV value was detected high and statistically significant $(20,21,7)$. In a study which compared 44 patients with pelvic inflammatory diseases to 44 patients in the control group, MPV values in patients with pelvic inflammatory disease were found to be low and statistically significant compared to the control group (8). In a study, which compared MPV values between ectopic pregnancy and healthy pregnancy groups, the MPV value levels in ectopic pregnancy group were found to be low but not statistically significant (9). There are many studies demonstrating the relationship between higher MPV and poor prognosis 
in patients with acute coronary syndrome (22). In this study, no statistically significant difference in MPV values between the patients with adnexal torsion and the control group was detected. A statistical relationship was not detected between MPV and platelet counts. MPV level may not have been affected due to the fact that ischemia in adnexal torsion is mechanic. The different results obtained in retrospective studies may be due to MPV's differences in standardization between the laboratories (23).

There is not yet a diagnosis method for the highly reliable preoperative diagnosis of adnexal torsion. Thus, torsion is not observed in some of the operations carried out with adnexal torsion pre-diagnosis, or delayed operations may cause loss of ovarian function.

In this study, the diagnostic importance of MPV in adnexal torsion, the diagnostic significance of which has been shown in many inflammatory and ischemic diseases so far, was investigated, and MPV was found not to be useful for the diagnosis of adnexal torsion. A large variety of case study series and prospective and retrospective researches should be carried out for further clarification of the subject.

Ethics Committee Approval: Ethics committee approval was received for this study the Institutional Ethical Committee of İnönü University.

Informed Consent: Written informed consent was obtained from patients who participated in this study.

Peer-review: Externally peer-reviewed.

Conflict of Interest: No conflict of interest was declared by the author.

Financial Disclosure: The author declared that this study has received no financial support.

\section{REFERENCES}

1. Hassan J, Tsafrir Z, Azein F, Bar-On S, Almong B, Mashiach R, et al. Comparison of adnexal torsion between pregnant and nonpregnant women. Am J Obstet Gynecol 2010;202:536. [CrossRef]

2. Huchon C, Fauconnier A. Adnexal torsion: a literature review. Eur J Obstet Gynecol Reprod Biol 2010;150:8-12. [CrossRef]

3. Rackow BW, Patrizio P. Successful pregnancy complicated by early and late adnexal torsion after in vitro fertilization. Fertil Steril 2007;87:697. [CrossRef]

4. Bar-On S, Mashiach R, Stockheim D, Soriano D, Goldenberg M, Schiff E, et al. Emergency laparoscopy for suspected ovarian torsion: are we too hasty to operate? Fertil Steril 2010;93:2012-5. [CrossRef]

5. Beyazit Y, Sayilir A, Torun S, Suvak B, Yesil Y, Purnak T, et al. Mean platelet volume as an indicator of disease severity in patients with acute pancreatitis. Clin Res Hepatol Gastroenterol 2012;36:162-8. [CrossRef]
6. Seker A, Incebiyik A, Kucuk A, Terzi A, Yucel Y, Ciftci R, et al. Platelet volume in patients with acute and chronic cholecystitis. Acta Medica Mediterranea 2013;29:515.

7. Narci H, Turk E, Karagulle E, Togan T, Karabulut K. The role of mean platelet volume in the diagnosis of acute appendicitis: a retrospective case-controlled study. Iran Red Crescent Med J 2013;15:e11934. [CrossRef]

8. Incebiyik A, Seker A, Vural M, Gul Hilali N, Camuzcuoglu A, Camuzcuoglu H. May mean platelet volume levels be a predictor in the diagnosis of pelvic inflammatory disease? Wien Klin Wochenschr 2014;126:422-6. [CrossRef]

9. Artunc Ulkumen B, Pala HG, Calik E, Oruc Koltan S. Can Mean Platelet Volume and Platelet Distrubition Width be Possible Markers for Ectopic Pregnancy and Tubal Rupture? (MPV and PDW in Ectopic Pregnancy). Pak J Med Sci 2014;30:352-5.

10. Houry D, Abbott JT. Ovarian torsion: a fifteen-year review. Ann Emerg Med 2001;38:156-9. [CrossRef]

11. Erdemoğlu M, Kuyumcuoglu U, Guzel AI. Clinical experience of adnexal torsion: evaluation of 143 cases. JExp Ther Oncol 2011;9:171-4.

12. Balci O, Icen MS, Mahmoud AS, Capar M, Colakoglu MC. Management and outcomes of adnexal torsion: a 5-year experience. Arch Gynecol Obstet 2011;284:643-6. [CrossRef]

13. Tobiume T, Shiota M, Umemoto M, Kotani Y, Hoshiai H. Predictive factors for ovarian necrosis in torsion of ovarian tumor. Tohoku J Exp Med 2011;225:211-4. [CrossRef]

14. Sommerville M, Grimes DA, Koonings PP, Campbell K. Ovarian neoplasms and the risk of adnexal torsion. Am J Obstet Gynecol 1991;164:577-8. [CrossRef]

15. Mazouni C, Bretelle F, Ménard JP, Blanc B, Gamerre M. Diagnosis of adnexal torsion and predictive factors of adnexal necrosis. Gynecol Obstet Fertil 2005;33:102-6. [CrossRef]

16. Descargues G, Tinlot-Mauger F, Gravier A, Lemoine JP, Marpeau L. Adnexal torsion: a report on forty-five cases. Eur J Obstet Gynecol Reprod Biol 2001;98:91-6. [CrossRef]

17. Chiou SY, Lev-Toaff AS, Masuda E, Feld RI, Bergin D. Adnexal torsion: new clinical and imaging observations by sonography, computed tomography, and magnetic resonance imaging. $J$ Ultrasound Med 2007;26:1289-301.

18. Park Y, Schoene N, Harris W. Mean platelet volume as an indicator of platelet activation: methodological issues. Platelets 2002;13:301-6. [CrossRef]

19. Gasparyan AY, Sandoo A, Stavropoulos-Kalinoglou A, Kitas GD. Mean platelet volume in patients with rheumatoid arthritis: the effect of anti-TNF- $\alpha$ therapy. Rheumatol Int 2010;30:1125-9. [CrossRef]

20. Albayrak Y, Albayrak A, Albayrak F, Yildirim R, Aylu B, Uyanik A, et al. Mean platelet volume: a new predictor in confirming acute appendicitis diagnosis. Clin Appl Thromb Hemost 2011;17:362-6. [CrossRef]

21. Bilici S, Sekmenli T, Göksu M, Melek M, Avci V. Mean platelet volume in diagnosis of acute appendicitis in children. Afr Health Sci 2011;11:427-32.

22. Leader A, Pereg D, Lishner M. Are platelet volume indices of clinical use? A multidisciplinary review. Ann Med 2012;44:805-16. [CrossRef]

23. Kartal O, Kartal AT. MPV: a reliable method to determine the prognosis? Ren Fail 2014;23:1. 